Bull. Mater. Sci., Vol. 36, No. 4, August 2013, pp. 513-516. (C) Indian Academy of Sciences.

\title{
Synthesis and up-conversion luminescence of $\mathrm{Yb}^{3+}-\mathrm{Ho}^{3+}$ co-doped $\mathrm{Na}\left(\mathbf{Y}_{1.5} \mathrm{Na}_{0.5}\right) \mathrm{F}_{6}$ nanorods
}

\author{
YANG YI ZHANG*, JING QUAN DENG and SHOU CHUN NI \\ Department of Electronics and Information Engineering, Chuzhou University, Anhui 239012, P. R. China
}

MS received 3 September 2011

\begin{abstract}
We present the optical up-conversion (UC) study for $\mathrm{Yb}^{3+}-\mathrm{Ho}^{3+}$ co-doped $\mathrm{Na}\left(\mathrm{Y}_{1.5} \mathrm{Na}_{0.5}\right) \mathrm{F}_{6}$ nanorods synthesized by employing a facile hydrothermal method. Numbers of $\mathrm{Ho}^{3+}$ ion up-conversion emissions have been observed under $980 \mathrm{~nm}$ infrared diode laser excitation. Three UC emissions of interest, ultraviolet, violet and blue,

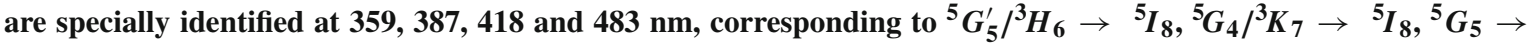
${ }^{5} I_{8}$ and ${ }^{5} F_{3} /{ }^{5} F_{2} /{ }^{3} K_{8} \rightarrow{ }^{5} I_{8}$ transitions, respectively. It is also found that the centre wavelength of blue UC emission shifts to $475 \mathrm{~nm}$ gradually as $\mathrm{Ho}^{3+}$ concentration decreases. Lastly, a brief analysis about $\mathrm{UC}$ mechanism is demonstrated according to the experimental results.
\end{abstract}

Keywords. $\mathrm{Na}\left(\mathrm{Y}_{1.5} \mathrm{Na}_{0.5}\right) \mathrm{F}_{6}$; nanorods; up-conversion.

\section{Introduction}

In recent years, rare-earth (RE) doped nanoscale materials have attracted tremendous interest due to their potential for applications in nanoscale optics and optoelectronics such as optical sensor, compact solid-state lasers and especially biological luminescent labels (Luo and Cao 2007; Wang et al 2009, 2010; Ji et al 2010; Zheng et al 2010). So far, UC emission properties of various $\mathrm{RE}^{3+}\left(\mathrm{Er}^{3+}, \mathrm{Tm}^{3+}, \mathrm{Yb}^{3+}, \mathrm{Ho}^{3+}\right.$ and $\mathrm{Gd}^{3+}$ ) ions doped fluoride materials at their strong frequency UC emissions have been well studied (Boyer et al 2007; Kumar et al 2009; Kim et al 2009; Cao et al 2010a, b). Among these trivalent $\mathrm{RE}$ ions, $\mathrm{Ho}^{3+}$ is of great interest as a result of its abundant energy levels, which are corresponding to the wide emissions spanning from ultraviolet to infrared. However, most of the researches are mainly focused on visible UC emissions (Martín et al 1998) and few investigations with attention paid onto short-wavelength UC emissions of $\mathrm{Ho}^{3+}$ ions have been reported. Recently, violet UC emission have been observed in nanoglass-ceramics comprising of $\mathrm{Yb}^{3+} / \mathrm{Ho}^{3+}$ co-doped $\mathrm{NaYF}_{4}$ nanocrystals under $980 \mathrm{~nm}$ laser excitation (Santana-Alonso et al 2010). Chen et al (2010) reported the shortest wavelength (247 and $290 \mathrm{~nm}$ ) of UC emissions in $\mathrm{Yb}^{3+} / \mathrm{Ho}^{3+}$ co-doped hexagonal $\mathrm{NaYF}_{4}$ powders under diode laser excitation of $970 \mathrm{~nm}$ (Chen et al 2010).

Among all the UC host materials, fluoride hosts are strong and efficient up-converters owing to low phonon energies, adequate thermal and environmental stability (Wang et al 2008a, b). $\mathrm{NaYF}_{4}$ (Boyer et al 2006; Cao et al 2010a, b), as a kind of fluoride host, is regarded as one of the most excellent host lattices for UC luminescence. It is known that $\mathrm{NaYF}_{4}$

\footnotetext{
*Author for correspondence (yyzhan@ hotmail.com)
}

mainly exhibits two polymorphic forms, which are cubic and hexagonal phases. Previous studies showed that the hexagonal phase of $\mathrm{NaYF}_{4}$ is much better than cubic phase $\mathrm{NaYF}_{4}$ in UC luminescence (Liu et al 2006). Recently reported that $\mathrm{NaYF}_{4}$ with different phase, shape and size have been synthesized by tuning the hydrothermal temperature, time and amount of $\mathrm{NaOH}$ (Zhang et al 2009).

In this work, we report highly uniform $\mathrm{Yb}^{3+}-\mathrm{Ho}^{3+}$ co-doped hexagonal $\mathrm{Na}\left(\mathrm{Y}_{1.5} \mathrm{Na}_{0.5}\right) \mathrm{F}_{6}$ one-dimensional nanorods synthesized using a simple hydrothermal approach. Under $980 \mathrm{~nm}$ excitation, as-prepared nanorods emit ultraviolet-to-visible UC fluorescence. The corresponding UC mechanisms have been proposed and discussed.

\section{Experimental}

Rare-earth nitrates $\mathrm{Y}\left(\mathrm{NO}_{3}\right)_{3} \cdot 6 \mathrm{H}_{2} \mathrm{O}, \mathrm{Ho}\left(\mathrm{NO}_{3}\right)_{3} \cdot 6 \mathrm{H}_{2} \mathrm{O}$ and $\mathrm{Yb}\left(\mathrm{NO}_{3}\right)_{3} \cdot 6 \mathrm{H}_{2} \mathrm{O}$ were of high purity $(>99.99 \%)$ and other chemicals like $\mathrm{NaF}, \mathrm{NaOH}$, ethanol and oleic acid were of analytical grade. The samples used in this work were prepared by facile hydrothermal method, which can be reffered to in Wang and Li (2007) and Zhang et al (2007) with some subtle modifications. First, accurately weighed $0.35 \mathrm{~g}$ $(8.75 \mathrm{mmol})$ of $\mathrm{NaOH}, 8 \mathrm{ml}$ oleic acid $(90 \mathrm{wt} \%)$ and $12 \mathrm{ml}$ ethanol were mixed well to get a white viscous solution. Then, $8 \mathrm{ml}$ of $\mathrm{NaF}(0.5 \mathrm{M})$ solution and $1.5 \mathrm{ml}(1.2 \mathrm{mmol})$ of rare-earth nitrate were added into the solution with vigorous stirring. After $30 \mathrm{~min}$ aging, the resulting solution was transferred into $25 \mathrm{ml}$ teflon bottle held in a stainless steel autoclave, sealed and hatched at $170{ }^{\circ} \mathrm{C}$ for $24 \mathrm{~h}$. When the system was naturally cooled down to room temperature, the obtained products were washed with ethanol and deionized 
water in sequence for several times to remove oleic acid and other remnants and then dried at $60^{\circ} \mathrm{C}$ for another $24 \mathrm{~h}$.

The crystal structures and phase purity of the sample were examined by $\mathrm{X}$-ray diffraction (XRD) with $\mathrm{Cu} \mathrm{K} \alpha$ radiation $(\lambda=1.5406 \AA)$ in the range of $10^{\circ} \leq 2 \theta \leq 85^{\circ}$. Morphology and size of the samples were characterized by scanning electron microscopy (SEM). UC spectra were picked by spectrophotometer under $980 \mathrm{~nm}$ laser excitation with variable power. All measurements were performed at room temperature.

\section{Results and discussion}

Figure 1(a) shows SEM image of the as-prepared nanorods. These nanorods display uniform morphology with about $1260 \mathrm{~nm}$ in length and $280 \mathrm{~nm}$ in diameter. XRD pattern of the as-prepared $\mathrm{NaY}_{0.8-x} \mathrm{Yb}_{0.2} \mathrm{Ho}_{x} \mathrm{~F}_{4}(x=0.25 \%)$ in figure 1(b) exhibits that sample crystallized in the hexagonal $\beta-\mathrm{Na}\left(\mathrm{Y}_{1.5} \mathrm{Na}_{0.5}\right) \mathrm{F}_{6}$ structure with space group $P 6_{3} / m$,
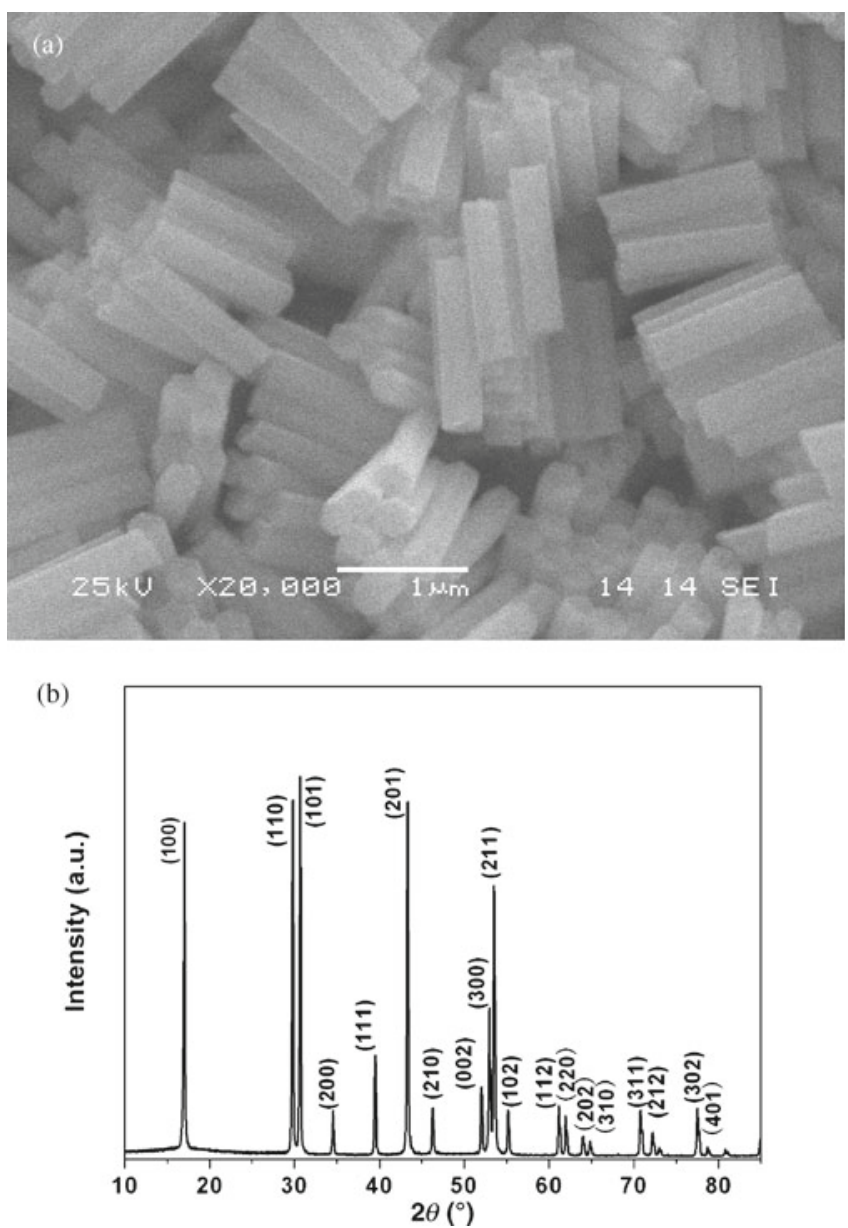

Figure 1. (a) SEM image of $\mathrm{Na}\left(\mathrm{Y}_{1.5} \mathrm{Na}_{0.5}\right) \mathrm{F}_{6}: \mathrm{Yb}^{3+}, \mathrm{Ho}^{3+}$ nanorods and (b) XRD pattern of as-prepared $\mathrm{Na}\left(\mathrm{Y}_{1.5} \mathrm{Na}_{0.5}\right) \mathrm{F}_{6}$ nanorods co-doped with $20 \mathrm{~mol} \% \mathrm{Yb}^{3+}$ and $0.25 \mathrm{~mol}^{2} \mathrm{Ho}^{3+}$ ions. is consistent with the standard X-ray diffraction (JCPDS 16-0334). No second phase is detected in XRD pattern, revealing that the high pure hexagonal phase of $\mathrm{Na}\left(\mathrm{Y}_{1.5} \mathrm{Na}_{0.5}\right) \mathrm{F}_{6}$ has been fabricated. The lattice constants were calculated in terms of XRD data and the lattice is of size $a=b=6.00$ and $c=3.49 \AA$.

Figure 2 shows UC emission spectrum of $\mathrm{Yb}^{3+} / \mathrm{Ho}^{3+}$ $\left(20 / 0.25\right.$ mol\%) co-doped $\mathrm{Na}\left(\mathrm{Y}_{1.5} \mathrm{Na}_{0.5}\right) \mathrm{F}_{6}$ nanorods, excited by $980 \mathrm{~nm}$ diode laser (power $\approx 238 \mathrm{~mW}$ ). An intense green emission centred at about $539 \mathrm{~nm}$ is observed, which is ascribed to the ${ }^{5} S_{2} /{ }^{5} F_{4} \rightarrow{ }^{5} I_{8}$ transition of $\mathrm{Ho}^{3+}$. The red and blue emissions approximately centred at 750 , 645 and $483 \mathrm{~nm}$ are assigned to ${ }^{5} S_{2} /{ }^{5} F_{4} \rightarrow{ }^{5} I_{7},{ }^{5} F_{5} \rightarrow{ }^{5} I_{8}$ and ${ }^{5} F_{3} /{ }^{5} F_{2} /{ }^{3} K_{8} \rightarrow{ }^{5} I_{8}$ transitions, respectively. Besides red, green and blue emissions, violet and ultraviolet UC emissions at 418, 387, $359 \mathrm{~nm}$ corresponding to ${ }^{5} G_{5} \rightarrow{ }^{5} I_{8}$, ${ }^{5} G_{4} /{ }^{3} K_{7} \rightarrow{ }^{5} I_{8}$ and ${ }^{5} G_{5}^{\prime} /{ }^{3} H_{6} \rightarrow{ }^{5} I_{8}$ transitions of $\mathrm{Ho}^{3+}$ ions are also detected. The inset of figure 2 shows a digital photograph of UC luminescence in ethanol solutions (1 wt \%) of $\mathrm{Na}\left(\mathrm{Y}_{1.5} \mathrm{Na}_{0.5}\right) \mathrm{F}_{6}: 20 \% \mathrm{Yb}^{3+}, 0.25 \% \mathrm{Ho}^{3+}$.

To understand UC emission mechanisms, we studied the pump power dependence of luminescence intensity. Generally, for an unsaturated UC luminescence, the number of photons that needs to populate the upper emitting state can be estimated by the following relation: $I_{\mathrm{UC}} \propto I_{\mathrm{P}}^{\mathrm{n}}$, where $I_{\mathrm{UC}}$ is the UC luminescence intensity, $I_{\mathrm{P}}$ the pumping power and $n$ the number of pumping photons required (Cao et al 2010a, b). Figure 3 shows double-logarithmic plots of $I_{\mathrm{UC}}$ vs $I_{\mathrm{P}}$. The slopes of the linear fittings are 1.63, 1.81, 1.66 and 2.58, respectively for $750,645,539$ and $483 \mathrm{~nm}$. The $483 \mathrm{~nm}$ band exhibits approximately cubic power law behaviours vs pumping power, indicating this emission is obtained through a three-photon process. The other three emission bands approximately exhibit quadratic power law behaviours vs

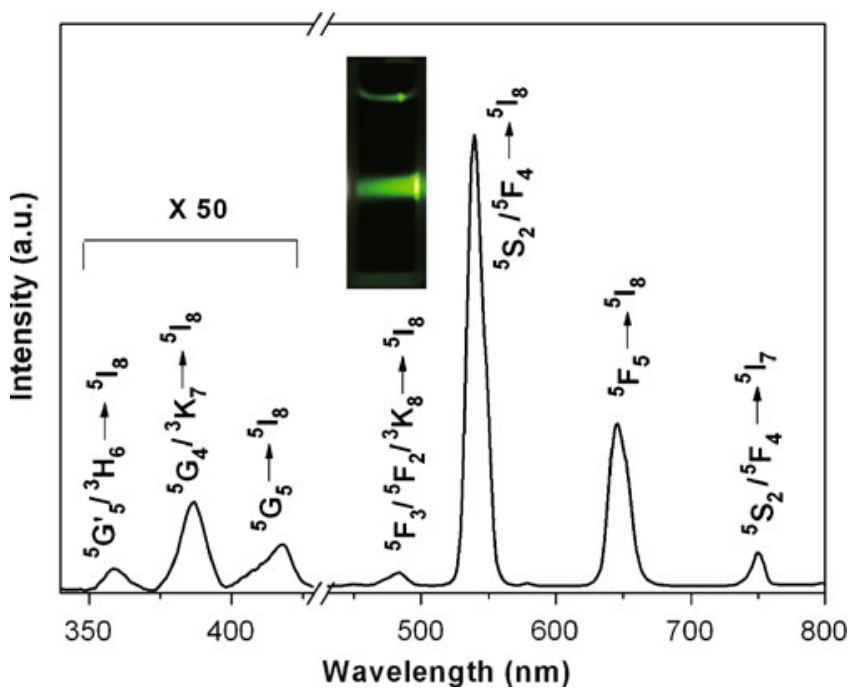

Figure 2. Room temperature UC emission spectrum of $\mathrm{Na}\left(\mathrm{Y}_{1.5} \mathrm{Na}_{0.5}\right) \mathrm{F}_{6}$ co-doped with $20 \mathrm{~mol} \% \mathrm{Yb}^{3+}$ and $0.25 \mathrm{~mol} \%$ $\mathrm{Ho}^{3+}$ under $980 \mathrm{~nm}$ excitation at $238 \mathrm{~mW}$. Inset shows photograph of nanonods dissolved in ethanol and excited with $980 \mathrm{~nm}$ laser. 


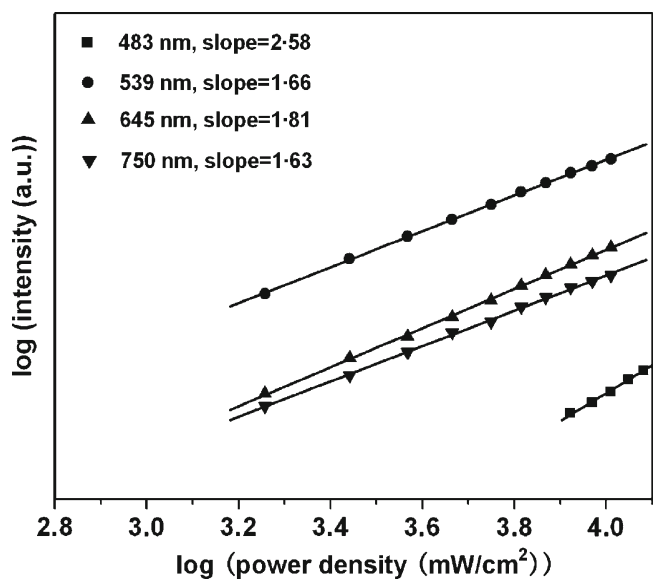

Figure 3. Double-logarithmic plot of excitation power dependent luminescence intensity in $20 \mathrm{~mol}^{2} \mathrm{Yb}^{3+}$ and $0.25 \mathrm{~mol}^{2} \mathrm{Ho}^{3+} \mathrm{co}-$ doped $\mathrm{Na}\left(\mathrm{Y}_{1.5} \mathrm{Na}_{0.5}\right) \mathrm{F}_{6}$ nanorods.

pumping power, indicating these processes are caused by two-photon absorption.

UC mechanisms in $\mathrm{Yb}-\mathrm{Ho}$ system have been studied in many host materials (Gouveia-Neto et al 2008; Naccache et al 2009). Figures 4 and 5 shows partial energy level diagrams of $\mathrm{Yb}^{3+}$ and $\mathrm{Ho}^{3+}$ ions as well as possible proposed UC mechanism. First, $\mathrm{Yb}^{3+}$ ions are excited to ${ }^{2} F_{5 / 2}$ level through ground state absorption process when $980 \mathrm{~nm}$ photon is absorbed. After that, via subsequent non-resonant excited state absorption (ESA) and energy transfer (ET) processes, $\mathrm{Ho}^{3+}$ ions are excited to ${ }^{5} S_{2},{ }^{5} F_{4}$ levels. Radiation emissions from ${ }^{5} S_{2},{ }^{5} F_{4}$ levels to ground state ${ }^{5} I_{8}$ with green emission at $540 \mathrm{~nm}$ or to ${ }^{5} I_{7}$ level with red emission at $750 \mathrm{~nm}$. On the other side, from ${ }^{5} S_{2},{ }^{5} F_{4}$ levels, a third pump photon is absorbed to populate ${ }^{5} G_{3}$ level and then decays to $\left({ }^{5} G_{5}^{\prime},{ }^{3} H_{6}\right),\left({ }^{5} G_{4},{ }^{3} K_{7}\right),{ }^{5} G_{5}$ and $\left({ }^{5} F_{3},{ }^{5} F_{2},{ }^{3} K_{8}\right)$ levels by non-radiative multi-phonon relaxation (Santana-Alonso et al 2010), with corresponding violet, blue emissions at 359, 387, 418 and $484 \mathrm{~nm}$ when ions de-excite to the ground state ${ }^{5} I_{8}$. In addition, there are two ways that may be responsible for the population of ${ }^{5} F_{5}$ level. One is by non-radiative multiphonon relaxation process from ${ }^{5} F_{4},{ }^{5} S_{2}$ levels. The other is that $\mathrm{Ho}^{3+}$ in ${ }^{5} I_{6}$ excited state relaxes non-radiatively to the intermediate level ${ }^{5} I_{7} . \mathrm{Ho}^{3+}$ in ${ }^{5} I_{7}$ level absorbs a second pumping photon through ESA/ET process and reaches ${ }^{5} F_{5}$ level.

UC spectra of as-prepared $\mathrm{Na}\left(\mathrm{Y}_{1.5} \mathrm{Na}_{0.5}\right) \mathrm{F}_{6}$ nanorods with fixed $\mathrm{Yb}^{3+}$ concentration and variable $\mathrm{Ho}^{3+}$ content were also investigated. From figure 4(a), the intensity of all emission bands were observed to increase as $\mathrm{Ho}^{3+}$ concentration increases. Moreover, for blue emission, the peak of wavelength shifts to $475 \mathrm{~nm}$, when $\mathrm{Ho}^{3+}$ ions concentration decreases to $0.05 \mathrm{~mol} \%$. Blue co-operative UC emission around $475 \mathrm{~nm}$ has been reported in $\mathrm{Yb}^{3+}$ doped hexagonal $\mathrm{NaYF}_{4}$ crystals (Wang et al 2008a, b). We also observed blue emission centred at $475 \mathrm{~nm}$ in $\mathrm{Na}\left(\mathrm{Y}_{1.5} \mathrm{Na}_{0.5}\right) \mathrm{F}_{6}: \mathrm{Yb}^{3+}(20 \mathrm{~mol} \%)$ under $980 \mathrm{~nm}$ excitation. It is explained that the blue emission luminescence is

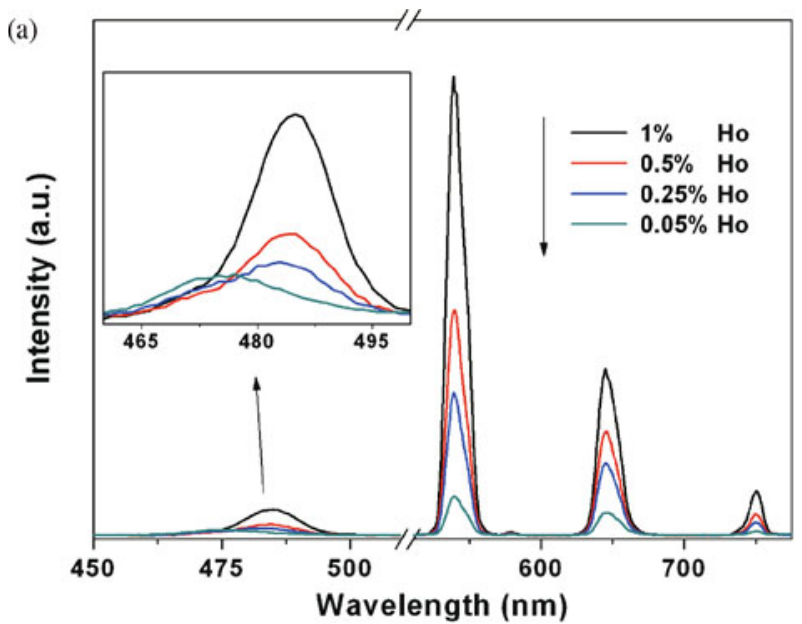

(b)

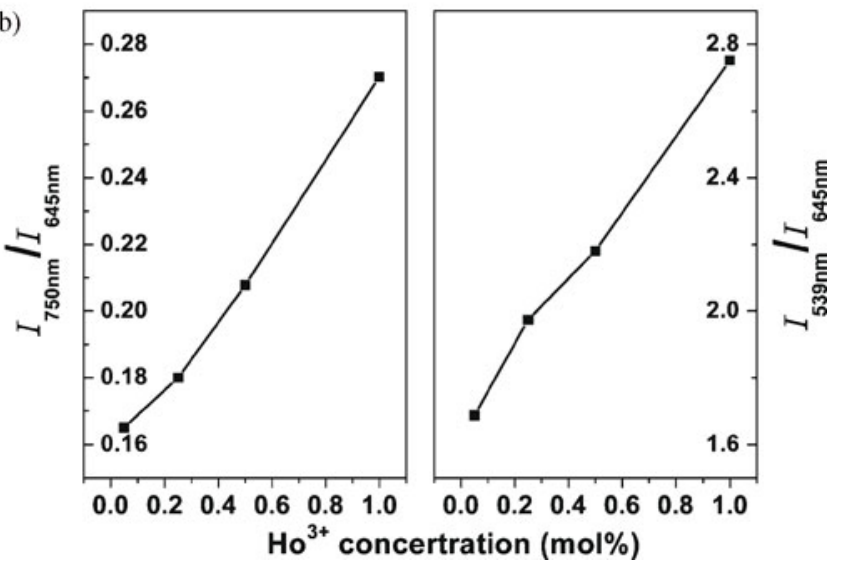

Figure 4. (a) Room temperature UC emission spectra of $\mathrm{Na}\left(\mathrm{Y}_{1.5} \mathrm{Na}_{0.5}\right) \mathrm{F}_{6}: \mathrm{Yb}^{3+} / \mathrm{Ho}^{3+}(20 / 0 \cdot 05-1 \mathrm{~mol} \%)$. Samples were excited at $980 \mathrm{~nm}$ with $73 \mathrm{~mW}$ laser and (b) UC emission peak intensity ratios, $I_{750 \mathrm{~nm}} / I_{645 \mathrm{~nm}}$ and $I_{539 \mathrm{~nm}} / I_{645 \mathrm{~nm}}$ as a function of $\mathrm{Ho}^{3+}$ concentration.



Figure 5. Energy-level diagram of $\mathrm{Yb}^{3+}-\mathrm{Ho}^{3+}$ ions system and possible mechanism for UC luminescence.

caused by the simultaneous radioactive relaxation of a pair of excited $\mathrm{Yb}^{3+}$ ions accompanied by a photon in the following process (Nakazawa and Shionoya 1970): ${ }^{2} F_{5 / 2}\left(\mathrm{Yb}^{3+}\right)+$ ${ }^{2} F_{5 / 2}\left(\mathrm{Yb}^{3+}\right) \rightarrow{ }^{2} F_{7 / 2}\left(\mathrm{Yb}^{3+}\right)+{ }^{2} F_{7 / 2}\left(\mathrm{Yb}^{3+}\right)+h v$. So in 
$\mathrm{Yb}^{3+} / \mathrm{Ho}^{3+}$ co-doped $\mathrm{Na}\left(\mathrm{Y}_{1.5} \mathrm{Na}_{0.5}\right) \mathrm{F}_{6}$ nanorods, with $\mathrm{Ho}^{3+}$ ions decreasing, the densities of $\mathrm{Yb}^{3+}-\mathrm{Yb}^{3+}$ ion pairs would be correspondingly increased, so that they could lead the centre wavelength of blue emission shifts to $475 \mathrm{~nm}$ gradually. In addition, the peak intensity ratios, $I_{539 \mathrm{~nm}} / I_{645 \mathrm{~nm}}$ and $I_{750 \mathrm{~nm}} / I_{645 \mathrm{~nm}}$ were depicted in figure $4(\mathrm{~b})$. With the increase of $\mathrm{Ho}^{3+}$ concentration, these ratios increase gradually. ET probability $(S)$ can be written as $S=N_{\mathrm{D}} N_{\mathrm{A}} W_{\mathrm{ET}}$, where $N_{\mathrm{D}}$ and $N_{\mathrm{A}}$ are the densities of donor and acceptor states and $W_{\mathrm{ET}}$ represents ET rate (Xiao et al 2004). It is obvious that as donor $\mathrm{Ho}^{3+}$ ions increase, the probability of ET would be increased correspondingly. Additionally, ${ }^{5} F_{5}$ state via non-radiative decaying from ${ }^{5} F_{4},{ }^{5} S_{2}$ levels requires several phonons to bridge the gap between these energy levels and does not contribute significantly to the enhancement of ${ }^{5} F_{5}$ red emission (Naccache et al 2009). As a result, 539 and $750 \mathrm{~nm}$ emissions increase rather than $650 \mathrm{~nm}$.

\section{Conclusions}

In conclusion, $\mathrm{Yb}^{3+} / \mathrm{Ho}^{3+}$ co-doped $\mathrm{Na}\left(\mathrm{Y}_{1.5} \mathrm{Na}_{0.5}\right) \mathrm{F}_{6}$ nanorods were synthesized by simple hydrothermal method. Under $980 \mathrm{~nm}$ excitation, ultraviolet-to-red UC emissions were observed. In addition, UC mechanism was discussed. For the $\mathrm{Yb}^{3+} / \mathrm{Ho}^{3+}$ co-doped $\mathrm{Na}\left(\mathrm{Y}_{1.5} \mathrm{Na}_{0.5}\right) \mathrm{F}_{6}$ nanorods, ultraviolet, violet, blue, green and red UC fluorescence can be attributed to the transitions ${ }^{5} G_{5}^{\prime} /{ }^{3} H_{6} \rightarrow{ }^{5} I_{8}$, ${ }^{5} G_{4} /{ }^{3} K_{7} \rightarrow{ }^{5} I_{8},{ }^{5} G_{5} \rightarrow{ }^{5} I_{8},{ }^{5} F_{3} /{ }^{5} F_{2} /{ }^{3} K_{8} \rightarrow{ }^{5} I_{8},{ }^{5} S_{2} /$ ${ }^{5} \mathrm{~F}_{4} \rightarrow{ }^{5} I_{8},{ }^{5} \mathrm{~F}_{5} \rightarrow{ }^{5} I_{8}$ and ${ }^{5} \mathrm{~S}_{2} /{ }^{5} \mathrm{~F}_{4} \rightarrow{ }^{5} \mathrm{I}_{7}$ of $\mathrm{Ho}^{3+}$, respectively. Due to co-operative $\mathrm{UC}$, the peak of blue emission shifts to lower frequency with decreasing $\mathrm{Ho}^{3+}$ concentration. Our results indicate that this kind of rare-earth doped hexagonal $\mathrm{Na}\left(\mathrm{Y}_{1.5} \mathrm{Na}_{0.5}\right) \mathrm{F}_{6}$ nanorods have promising applications in nanoscale optical sensors, displays and solid-state lasers.

\section{Acknowledgements}

This work was partially supported by the Open Project Program (Grant No. 2008-8) of State Key Laboratory of Silicon Materials, Zhejiang University; the Natural Science Project of Chuzhou University (No.2011kj016B); and the Provincial Project of Natural Science Research for Colleges and
Universities of Anhui Province of China (No.KJ2013B184 and No.KJ2012B127).

\section{References}

Boyer J C, Vetrone F, Cuccia L A and Capobianco J A 2006 J. Am. Chem. Soc. 1287444

Boyer J C, Cuccia L A and Capobianco J A 2007 Nano. Lett. 7847 Cao C Y, Qin W P and Zhang J S 2010a Opt. Commun. 283547

Cao T Y, Yang T S, Gao Y, Yang Y, Hu H and Li F Y 2010b Inorg. Chem. Commun. 13392

Chen G Y, Yang C H, Aghahadi B, Liang H J, Liu Y, Li L and Zhang Z G 2010 J. Opt. Soc. Am. B27 1158

Gouveia-Neto A S, Bueno L A, Afonso A C M, Nascimento J F, Costa E B, Messaddeq Y and Ribeiro S J L 2008 J. Non-Cryst. Solids $\mathbf{3 5 4} 509$

Ji T H, Liu Y, Zhao H, Du H Y, Sun J Y and Ge G L 2010 J. Solid State Chem. 183584

Kim W J, Nyk M and Prasad P N 2009 Nanotechnology 20 18531

Kumar R, Nyk M, Ohulchanskyy T Y, Flask C A and Prasad P N 2009 Adv. Funct. Mater. 19853

Liu F, Ma E, Chen D Q, Yu Y L and Wang Y S 2006 Phys. Chem. B110 20843

Luo X X and Cao W H 2007 Mater. Lett. 613696

Martín I R, Rodríguez V D, Lavín V and Rodríguez-Mendoza U R 1998 J. Alloys Compd. 275-277 345

Nakazawa E and Shionoya S 1970 Phys. Rev. Lett. 251710

Naccache R, Vetrone F, Mahalingam V, Cuccia L A and Capobianco J A 2009 Chem. Mater. 21717

Santana-Alonso A, Méndez-Ramos J, Yanes A C, Del-Castillo J and Rodríguez V D 2010 Opt. Mater. 32903

Wang L Y and Li Y D 2007 Chem. Mater. 19727

Wang G F, Qin W P, Wang L L, Wei G D, Zhu P F and Kim R J 2008a Opt. Express 1611907

Wang X F, Xiao S G, Yang X L and Ding J W 2008b J. Mater. Sci. 431354

Wang G F, Peng Q and Li Y D 2009 J. Am. Chem. Soc. 131 14200

Wang J, Wang F, Xu J, Wang Y, Liu Y S, Chen X Y, Chen H Y and Liu H Y 2010 C. R. Chimie. 13731

Xiao S G, Yang X L, Liu Z W and Yan X H 2004 J. Appl. Phys. 96 1360

Zhang F, Li J, Shan J, Xu L and Zhao D Y 2009 Chem. Eur. J. 15 11010

Zhang F et al 2007 Angew. Chem. 1198122

Zheng K Z, Wang L L, Zhang D S, Zhao D and Qin W P 2010 Opt. Express 182934 